\title{
Förderung der Zahn- und Mundhygiene bei Menschen mit Behinderung
}

Menschen mit Behinderung haben häufig im Vergleich zum Bevölkerungsdurchschnitt eine schlechtere Mundgesundheit. Daher ist es sinnvoll, dass zahnmedizinische Prophylaxe-Maßnahmen besondere Berücksichtigung finden. Je nach Schweregrad der Behinderung ist bei der täglichen Mundhygiene Hilfe durch Betreuer oder Angehörige erforderlich. Deshalb ist es wichtig, diese Vertrauenspersonen in die praktische Umsetzung häuslicher Prophylaxe-Maßnahmen einzubeziehen und sie über adäquate Hilfsmittel zur Unterstützung der Zahn- und Mundpflege aufzuklären. Neben regelmäßigen zahnme- dizinischen Vorsorgeuntersuchungen und Fluoridierungsmaßnahmen, ist gerade auch die tägliche häusliche Zahnpflege mit geeigneten prophylaktischen Hilfsmitteln ein Schlüssel zum langfristigen Erhalt der Mundgesundheit. Mundspülungen mit ätherischen Ölen bieten eine wertvolle Ergänzung der mechanischen Zahnreinigung. Sie erreichen auch schwer zugängliche Bereiche des Mundraums, die bei der mechanischen Zahnreinigung unberücksichtigt bleiben können.

Im Rahmen der Sportveranstaltung Special Olympics Deutschland, die vom 6.-10. Juni in Hannover stattfand, unter-

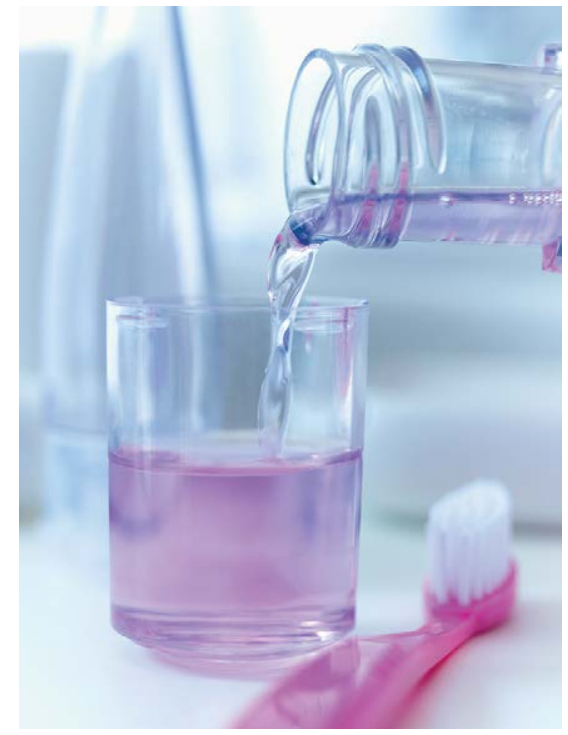

stütze Listerine das zahnmedizinische Gesundheitsprogramm „Special Smiles“ mit der Abgabe Proben an die teilnehmenden Athleten.

Nach einer Pressemitteilung der Johnson \& Johnson GmbH, Neuss 